Article

\title{
The Role of Emotional Intelligence Factors in Workers' Occupational Health and Safety Performance-A Case Study of the Petroleum Industry
}

\author{
Augustine O. Ifelebuegu *(D), Oluwakemi A. Martins, Stephen C. Theophilus \\ and Andrew O. Arewa \\ School of Energy, Construction and Environment, Coventry University, Coventry CV1 5FB, UK; \\ martinso@uni.coventry.ac.uk (O.A.M.); ab2038@coventry.ac.uk (S.C.T.); ab6887@coventry.ac.uk (A.O.A.) \\ * Correspondence: A.Ifelebuegu@coventry.ac.uk
}

Received: 12 April 2019; Accepted: 10 May 2019; Published: 17 May 2019

\begin{abstract}
Introduction: Despite improvements in occupational health and safety due to technological advancements and the adoption of management systems, accidents continue to occur in the oil and gas $(O \& G)$ industry. These accidents are often linked to human factors. The emotional intelligence (EI) of workers, however, has the potential to influence some of the human factors that predispose to accidents. Methods: In this study, we investigated how the EI factors of workers influence their health and safety performance in the work place. A total of $124 \mathrm{O} \& \mathrm{G}$ industry workers completed a web-based questionnaire. Five and 14 key success factors of EI and effective occupational health and safety management systems were respectively identified through a systematic evaluation of the literature. Results: EI success factors of 'being able to rule one's own emotions to facilitate thinking', 'being able to deal with the emotions of others' and 'being able to discuss one's own emotions accurately' were found to have a relationship with health and safety performance of workers. Conclusion: The findings demonstrated that certain success factors of EI are vital for improving the health and safety performance of workers and that the development of these competencies should be part of the workers' professional development.
\end{abstract}

Keywords: safety; emotional intelligence; oil and gas; safety performance

\section{Introduction}

The oil and gas industry is comprised of highly complex systems which require the interaction of technical, social, organisational, human, managerial and environmental factors. 'Fall out' in any of these factors can lead to a catastrophic event [1,2]. The emergence of occupational health and safety management systems to help in the identification of hazards in the workplace has made a substantial impact on both the performance and the safety of oil and gas industry workers. A review of the literature has shown that the major areas where hazards might develop in the workplace can be grouped into the physical workplace, the people and the management [3-5]. From a physical workplace perspective, mechanical, structural and process design failures are possible occurrences [6,7]. From a people perspective, negligence and carelessness have often been among the key causes of accidents [8]. Most crucial, however, is the management perspective which deals with the management's ability to make decisions to ensure the protection of the health and safety of the workers and their environment [8].

Mearns and Yule [9], considering the nature of business in the oil and gas industry and the chemical and complex processes involved, have described the industry as high-risk. Attwood et al. [10] suggested that accident causation may be divided into three categories, namely, human error, hardware failure and external events. Of the three, equipment malfunctioning has reduced significantly as 
a cause of accidents, because of the progress in technological advancements. This has consequently highlighted the role of the human element in accident causation, because accidents continue to occur, regardless of improvements in equipment design.

Furthermore, several health and safety regulations have been implemented over the years to improve occupational health and safety and reduce the occurrence of accidents and the incalculable loss of life. However, major accidents still occur, especially in the highly volatile oil and gas industry [11,12]. Incident investigations into several major disasters in the oil and gas industry including Piper Alpha, Exxon Valdez, the Macondo blowout and the BP Texas explosion have revealed that the underlying cause of these accidents was human error [5,13]. Having established this, it is therefore prudent to assign a considerable amount of resources to the understanding of the role of human error in accident causation and to gain an understanding of what leads employees to make particular errors that could be avoided [2,14]. Several studies have been conducted in this area, and theories have been put forward, including Behaviour-Based Safety (BBS), the Swiss Cheese model and Turner's model of accident causation, which all seek to measure and manage human error. Human action or behaviour is influenced by numerous factors including emotion, culture, attitude, authority, ethics, religion, genetics, health, chemical/biological influences, environment, mood, temperament, personality, motivation, disposition, training and experience $[15,16]$. Any lapse in any one of these factors may result in abnormal human behaviour, which in turn introduces a human hazard into a process [12]. While the significance of one factor does not necessarily outweigh the others, for the purpose of this paper, emotional intelligence factors will be the focus.

Emotional intelligence has been defined as the ability to understand, perceive and manage emotions [17]. It can be a direct or indirect derivative of many different factors [18]. Through the careful measurement and management of personal emotions, and indeed the emotions of others, it may be hoped to successfully influence or control human behaviour in order to achieve improved occupational health and safety performance $[16,19,20]$. In order to effectively manage hazards in the workplace, it is important that the critical success factors in occupational health and safety management systems be given strict attention in day-to-day operations. The challenge remains, however, that human error, negligence, carelessness and levels of intelligence affect the maintenance of stated standards of occupational health and safety during work routines [4,21,22]. Varying levels of emotional intelligence among workers are a major factor in determining workers' ability to uphold standards [23].

According to Green [24], 'smart emotions make smart people; smart people make smart decisions'. Emotions influence the way people act, behave, react and respond to issues around them. Responses to issues vary from one person to another because of different emotional dispositions. In other words, when a person is referred to as 'a smart person', the actual meaning is denoted as having 'smart emotions', which is often expressed in the person's ability to make smart decisions when needed. This ability can be referred to as emotional intelligence. The leading researchers that first published articles in the knowledge area of emotional intelligence were Salovey and Mayer [25] and Goleman [26]. Goleman [26] was one of the first researchers to publicly appraise the significance of emotional intelligence, making several claims as to its relationship to organisational performance. However, one of the challenges faced in the application of Goleman's claims for the implications for an organisation of emotional intelligence was the lack of a measurement medium for its assessment.

In 1997, a construct for measuring the operational index of emotional intelligence was developed $[27,28]$. The discovery of the importance of emotional intelligence to organisational performance has subsequently generated a considerable amount of research over the decades [29-31], resulting in the development of various definitions in a bid to provide a comprehensive meaning that encompasses all the various claims from the different researchers. Notwithstanding the various definitions of emotional intelligence generated by researchers across the literature, they have some key factors in common. To effectively identify and understand these key factors, it will be necessary to comprehend models of emotional intelligence and their impact on leadership and in the workplace. 
Models of Emotional Intelligence

Various models of emotional intelligence have been developed since the discovery of the knowledge area. These models include [32-36]:

- Salovey and Mayer (1990)

- Goleman (1995)

- Mayer and Salovey (1997)

- Bar-On (1997)

- Cooper and Sawaf (1997)

- Goleman (1998)

- Weisinger (1998)

- Higgs and Dulewicz (1999)

- Petrides and Furnham (2001)

- Goleman (2012) models of emotional intelligence

The Salovey and Mayer [25] model of emotional intelligence comprises three competencies: appraisal and expression of emotions, use of emotions and regulation of emotions. The expression of emotion deals with the ability of a person to generate emotions that are capable of influencing both the emotions and the actions of others [33]. The use of emotion entails the ability to achieve aims or set goals using emotional intelligence as a tool. The third competence of the Salovey and Mayer model of emotional intelligence refers to the ability to regulate emotions towards supporting a specific line of action [37]. Figure 1 below shows an illustrative representation of the Salovey and Mayer [25] model of emotional intelligence.

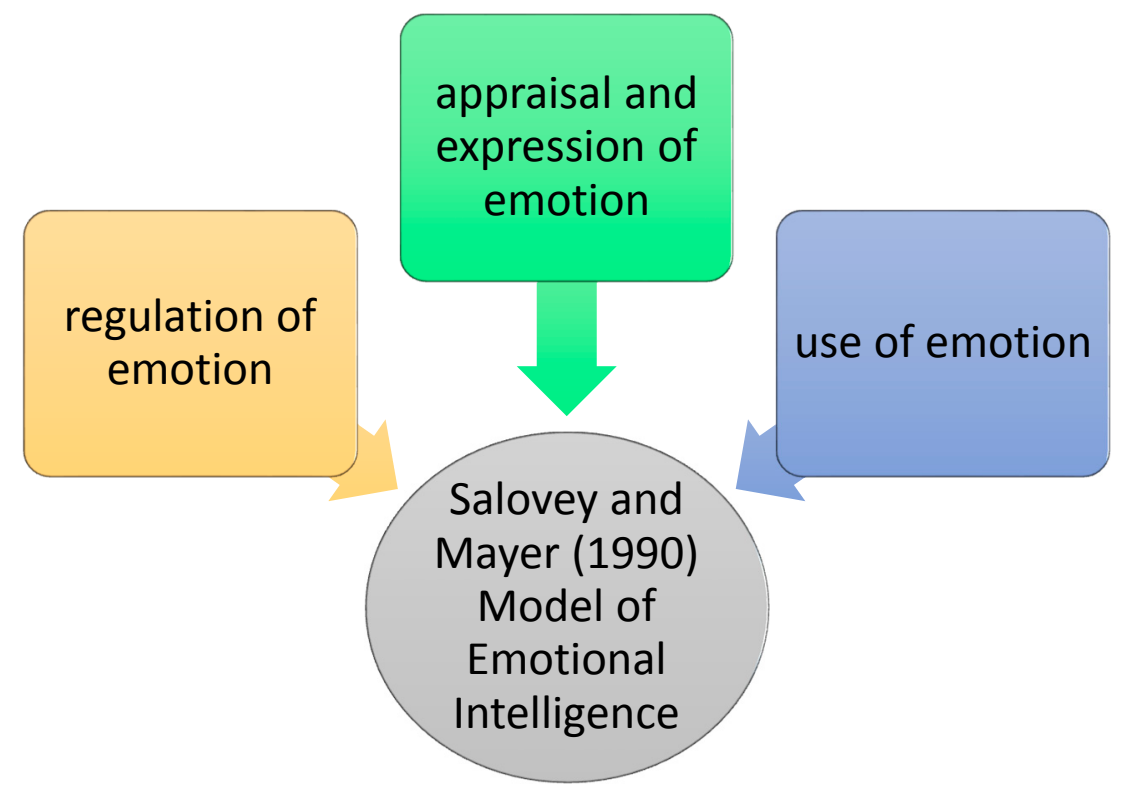

Figure 1. The Salovey and Mayer (1990) model of emotional intelligence (Adapted from Perez et al. 2004).

A more recent model of emotional intelligence is the Goleman 2012 model [38]. It comprises 4 principal domains and 19 confidences. The four domains include self-awareness, social awareness, self-management and relationship management. Figure 2 shows the four broad domains of emotional intelligence as developed by Goleman [38]. The 19 confidences included in the 4 broad domains are also shown.

From the foregoing, there is a need for the oil and gas industry to have a good knowledge of the role of emotional intelligence in improving the efficiency and performance of occupational health and 
safety. The main purpose of this study is to examine how employees' emotional intelligence factors influence their health and safety performance.

SELF

Self-awareness
RECOGNITION
Self-confidence,
Emotional self-awareness,
Accurate self-awareness,
Self-management
Self-control,
Trustworthiness,
Conscientiousness,
Adaptability,
Achievement,
DEGULATION
Drive to succeed,
Initiative,

SOCIAL

Social awareness

Empathy,

Organisational awareness,

Service orientation,



Figure 2. The four broad domains of emotional intelligence (Goleman 2012).

\section{Materials and Methods}

\subsection{Research Design}

This research study used multi-research strategies in order to systematically examine the case under investigation and utilise the full benefits of both quantitative and qualitative research [39]. The study systematically applied both primary and secondary data. The primary data were collected through a web-based survey questionnaire, while the secondary data were collected from journals, books, conference proceedings and other official publications. The information collected from secondary sources and the findings derived from its data were used as the basis for the design of the questionnaire. The survey questionnaire used a combination of closed-ended and open-ended questions to facilitate both the measurement and the data analysis $[39,40]$. The questionnaires were administered to a randomly selected number of oil and gas industry professionals across the upstream and downstream sectors. Care was taken to ensure that information was gathered from all levels of management to enhance the generalisation of the results. The questionnaire gathered information about the extent to which each of the key success factors of emotional intelligence represented the respondent's strength of emotional disposition in the workplace. Furthermore, information on how each of these key factors of emotional intelligence affected the respondent's level of commitment to each of the identified key success factors of occupational health and safety was also collected.

\subsection{Data Collection}

The sample selection was guided by the nature of the information required for meeting the research objectives. Therefore, this study concentrated on a randomly selected number of oil and gas professionals. A total of 124 responses were collected from 210 distributed questionnaires. A total of 110 participants were target on the basis of the sample design. Data on the participants' professions and their work experience were collected through the survey questionnaire. The following professions featured among the 124 participants: Safety Managers and Officers (30\%), Engineers (38\%), Geoscientists (12\%), Commercial and Administrators (7\%) and others (13\%). Also, the number of years 
of experience of the participants was $1-5$ years (22\%), 6-10 years (29\%), $10-15$ years $(33 \%)>15$ years $(16 \%)$. In the sample, $58 \%$ of the population was male, while $48 \%$ was female respondents.

\subsection{Data Analysis}

This research adopted a joint approach of both inductive and deductive methods of data analysis. In the determination of the key success factors of emotional intelligence, 10 models were systematically reviewed, and the commonalities among their competencies were categorised. Similarly, the key success factors of occupational health and safety were determined on the basis of a systematic review of the existing literature. Studies were independently selected in accordance with the PICO inclusion and exclusion criteria [41].

The statistical package for social sciences (SPSS) was used in evaluating the relationship between the emotional intelligence of the participants and their views on how emotional intelligence could affect the derived key success factors of occupational health and safety management systems. A regression analysis was conducted to determine the correlation coefficient of the variables and ascertain the strength of the relationship between emotional intelligence factors and occupational health and safety performance.

\section{Results}

\subsection{Key Success Factors of Occupational Health and Safety in the Workplace}

A critical and systematic evaluation of the past literature on occupational health and safety in the oil and gas industry was carried out to determine the success factors that are necessary for its effective performance. A review of the past literature showed that, notwithstanding considerable investment in occupational health and safety, safety performance will be undermined without a good understanding of the implications of the employees' emotional intelligence [42-46]. This study identified the following success indicators as key to effective occupational health and safety in the workplace:

(1) Level of understanding and perception of risks in the workplace

(2) Level of understanding of injury preventive measures in the workplace

(3) Level of understanding of security regulations in the workplace

(4) Level of understanding of the implications of risky work operations

(5) Level of compliance with rules and regulations guiding the use of health and safety personnel in the workplace

(6) Willingness to participate in the implementation of risk-reduction action plans in the workplace

(7) Willingness to participate in meetings pertaining to occupational health and safety measures in the workplace

(8) Willingness to participate in training provided by the organisation on safety regulations, new equipment and other changes in the workplace

(9) Level of understanding and compliance with new accident preventive measures provided by the company during periods of additional workloads

(10) Level of understanding and compliance with protective regulations for all machines and equipment used in the workplace

(11) Level of understanding of the use of personal safety devices provided in the workplace

(12) Level of understanding of the use of first aid equipment provided in the workplace

(13) Ability to make correct decisions in times of emergencies in the workplace

(14) Ability to take cognizance of a colleague's inability to make correct decisions in times of emergencies in the workplace 


\subsection{Key Success Factors of Emotional Intelligence}

One of the factors of emotional intelligence that was not included in the Goleman (2012) model is 'effective communication skills'. This was highlighted in Weisinger's [47] model of emotional intelligence and is defined as the ability to discuss personal emotions in such a way as to influence the emotions of others in a given direction of action. Two distinct attributes of the Weisinger model of emotional intelligence are 'effective communication skills' and 'emotional coaching' as fundamental competencies of the emotional intelligence construct that deals with the ability to convey emotions from one person to another. Some commonalities were observed in the competencies presented across all 10 models evaluated in this study. These common competencies fall under four key areas:

(1) Being aware of one's own emotions

(2) Being able to rule one's own emotions to facilitate thinking

(3) Being able to recognise the emotions of others at any given moment in time

(4) Being able to deal with the emotions of others

However, a gap was observed across most of the models, that should be incorporated into the above four key competencies to make up a fifth, namely, effective communicative skills/emotional coaching. This assertion was supported by Decker et al. [42] in a study that involved an exploration of the relationship between emotional intelligence and the use of knowledge transfer methods. The ability to discuss one's own emotions' was identified and used as a key factor of emotional intelligence required for an effective knowledge transfer. Consequently, the key success factors of emotional intelligence can now be presented to include:

(1) Being aware of one's own emotions

(2) Being able to rule one's own emotions to facilitate thinking

(3) Being able to recognise the emotions of others at any given moment in time

(4) Being able to deal with the emotions of others

(5) Being able to discuss one's own emotions accurately

\subsection{Key Success Factors of Emotional Intelligence that affect Oil and Gas Workplace Performance}

This section of the study analyses the strength of the respondents' emotional dispositions based on each of the key success factors of emotional intelligence in the workplace. This was measured using a five-point scale with these descriptors: 5-Large extent, 4-Moderate extent, 3-Some extent, 2-Little extent and 1-Not at all. The frequency distribution of the respondents' emotional dispositions as derived across the 124 oil and gas professionals is shown in Figure 3. 'Being aware of one's own emotions', which means 'having the ability to ascertain your emotions, thoughts, feelings and physical states' had the highest percentage of the rating scale of ' 5 -large extent', with a value of $61.02 \%$. This was succeeded by 'Being able to rule one's own emotions to facilitate thinking', with a value of $35.59 \%$ under the rating scale of ' 5 -large extent'. Under the rating of '4-moderate extent', 'Being able to rule one's own emotions to facilitate thinking' led with a value of $44.07 \%$. This study shows that the emotional dispositions of the majority of oil and gas professionals are more predominant in the following key factors of emotional intelligence: 'Being aware of one's own emotions' and 'Being able to rule one's own emotions to facilitate thinking'. 


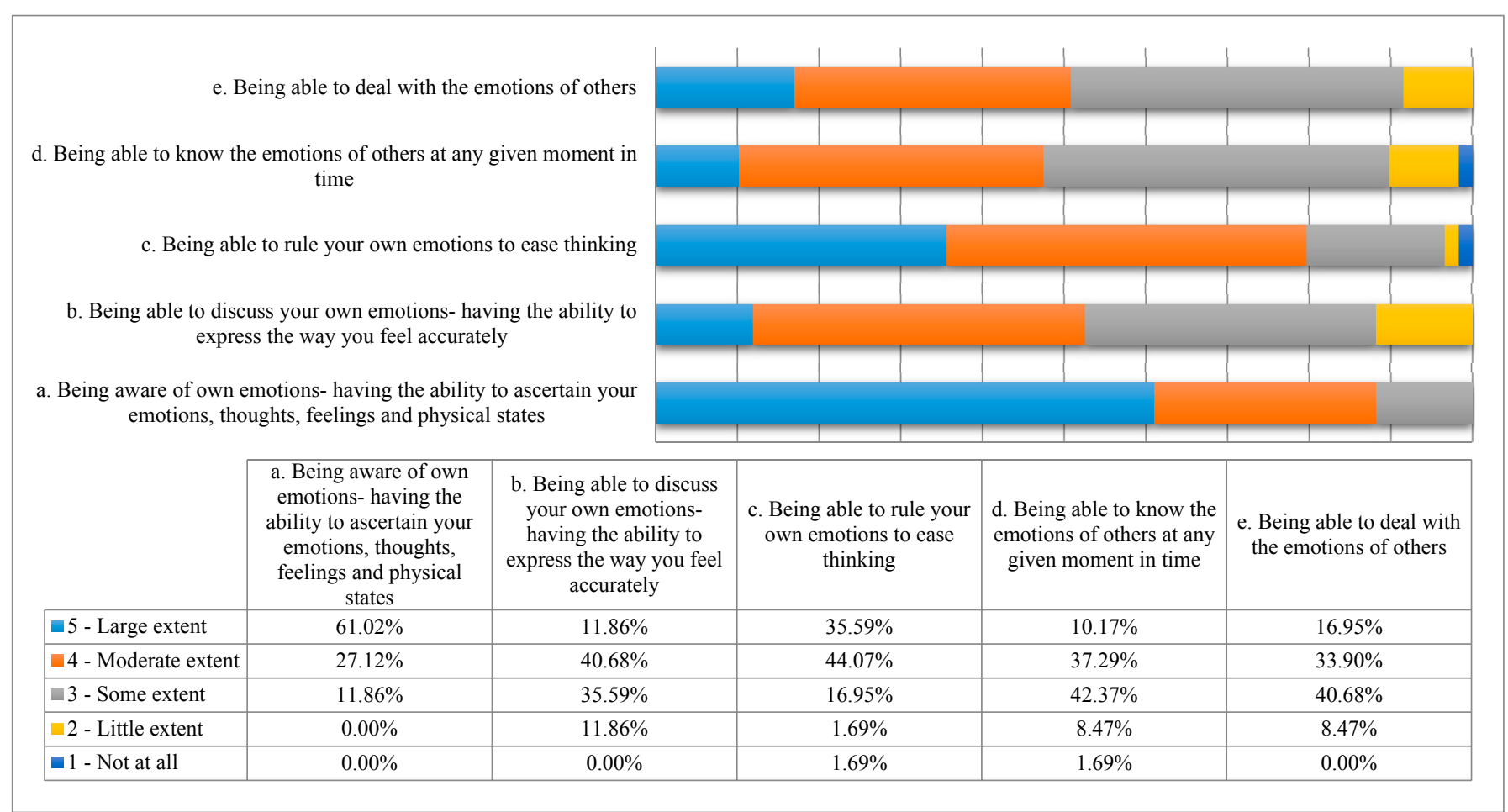

Figure 3. Frequency distribution (\%) of the participants' levels of emotional disposition based on the derived key success factors of emotional intelligence that affect oil and gas workplace performance. 
3.4. Key Success Factors for Effective Occupational Health and Safety Management in the Oil and Gas Industry

The extent to which the respondents' emotional dispositions affect their commitment to each of the key success factors of occupational health and safety was derived from the survey questionnaire. The oil and gas professionals were asked to indicate the extent to which their emotional intelligence affected their commitment to each of the key success factors of occupational health and safety management in their workplaces. Their responses were collected using a five-point scale with the following descriptors: 5-Large extent, 4-Moderate extent, 3-Some extent, 2-Little extent and 1-Not at all. The frequency distributions are presented in Figure 4. The study showed that the 'Ability to make the correct decision in times of emergencies in the workplace' was rated the highest by the participants, with a value of $61.02 \%$. This was followed by 'Level of understanding of injury preventive measures in the workplace', with a value of $57.63 \%$. A significant observation from the ratings placed on the extent to which workers' emotional intelligence affected their commitment to each of the key success factors was the allocation of a rating of $55.93 \%$ across three of them. These factors include:

(1) Level of understanding and perception of risks in the workplace

(2) Willingness to participate in the implementation of risk-reduction action plans in the workplace

(3) Ability to take cognizance of a colleague's inability to make correct decisions in times of emergencies in the workplace 


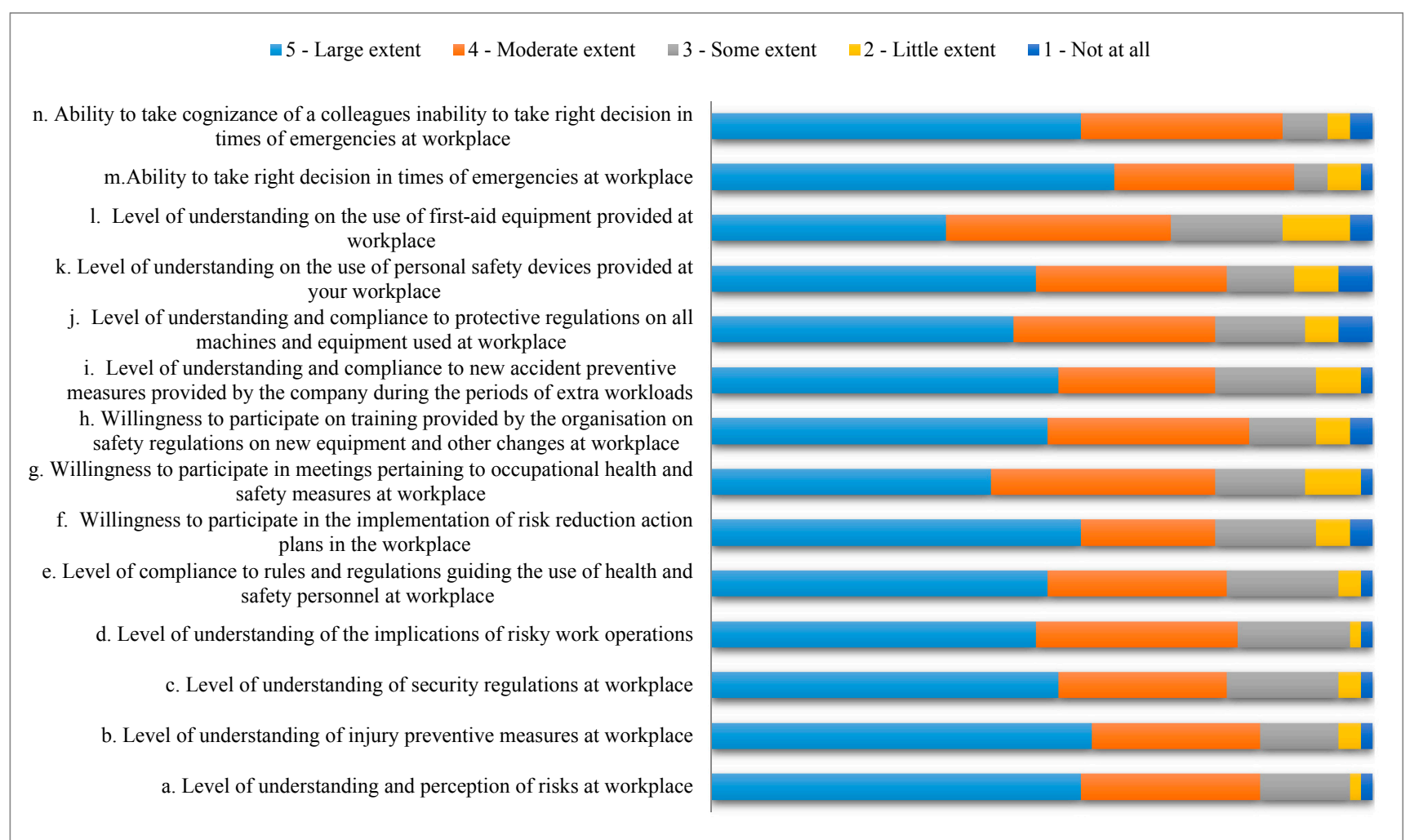

Figure 4. Frequency distribution (\%) of the extent to which workers' emotional intelligence affects their commitment to each of the key success factors of effective occupational health and safety management in the oil and gas industry. 


\subsection{Improving Occupational Health and Safety Performance using Emotional Intelligence in the Oil and Gas Industry}

To critically evaluate the effect of emotional intelligence on the management of occupational health and safety in the oil and gas industry, a regression analysis of the relationship between the respondents' emotional intelligence and how this affects their commitment to occupational health and safety practices was carried out using a confidence interval of $90 \%$. Furthermore, a multiple regression analysis to derive the individual correlation coefficients for this relationship was also conducted to help identify the effects of the key factors of emotional intelligence on occupational health and safety. Moreover, the multiple regressions also helped in finding the individual correlation coefficients for the relationship between emotional intelligence and the commitment to each of the key factors of occupational health and safety. In order to help interpret the correlation coefficients derived from the analysis, the Cohen guidelines for classifying correlation coefficients were used to interpret the values, as shown in Table 1.

Table 1. Guidelines for classifying correlation coefficients as developed by Cohen (1998).

\begin{tabular}{ccc}
\hline Absolute Value of $\mathbf{R}$ & R Squared & Size of Effect \\
\hline $0.1 \leq \mathrm{R}<0.30$ & $0.01 \leq \mathrm{R}^{2}<0.09$ & WEAK \\
$0.3 \leq \mathrm{R}<0.50$ & $0.09 \leq \mathrm{R}^{2}<0.25$ & MODERATE \\
$\mathrm{R} \geq 0.50$ & $\mathrm{R}^{2} \geq 0.25$ & STRONG \\
\hline A correlation less than 0.1 is trivial & & \\
A correlation between 0.1 and 0.3 has a WEAK association/strength of relationship \\
A correlation between 0.3 and 0.5 has a MODERATE association/strength of relationship \\
A correlation greater than or equal to 0.5 has a STRONG association/strength of relationship
\end{tabular}

The correlation coefficients were first derived for the oil and gas industry employees' commitment to occupational health and safety, their levels of emotional intelligence and the implications this has for their commitment to occupational health and safety. A correlation coefficient of 0.75 was derived, which depicts a strong relationship, based on the Cohen guidelines for classifying correlation coefficients. Moreover, a significance value of $0.009(0.009<0.05)$ was derived, showing that a strong relationship existed between the variables. In order to check the implications of the oil and gas industry's commitment to occupational health and safety on the derived 0.75 correlation coefficient, the analysis was repeated without including the data collected on 'implication of the oil and gas industry's commitment to occupational health and safety' as an independent variable. The result obtained showed the same value of 0.75 for the correlation coefficient and a stronger significance value of $0.008(0.008<0.009<0.05)$, hence indicating that the oil and gas industry's commitment to occupational health and safety has no effect on the extent to which emotional intelligence affects its effective management. Consequently, the multiple regression analysis for deriving the individual correlation coefficients for the relationship between emotional intelligence and its implications for the employees' commitment to each of the key factors of occupational health and safety was conducted only with the variables emotional intelligence and occupational health and safety, as shown in Table 2.

Table 2. Correlation coefficients for the relationship between emotional intelligence and the implication of workers' emotional intelligence on their commitment to each of the key factors of occupational health and safety.

\begin{tabular}{lcc}
\hline \multicolumn{1}{c}{ Model } & R & Strength of Relationship \\
\hline \multicolumn{1}{c}{ Success Factors of EI } & & Weak \\
\hline $\begin{array}{l}\text { Being aware of own emotions } \\
\text { Being able to rule your own emotions to ease thinking }\end{array}$ & 0.15 & Strong \\
time & 0.76 & Weak \\
Being able to deal with the emotions of others & 0.12 & Strong \\
Being able to discuss your own emotions accurately & 0.91 & Moderate \\
\hline
\end{tabular}


Table 2. Cont.

\begin{tabular}{|c|c|c|}
\hline Model & $\mathbf{R}$ & Strength of Relationship \\
\hline \multicolumn{3}{|l|}{ Success Factors of $\mathrm{OH}$ and $\mathrm{S}$} \\
\hline Level of understanding and perception of risks at workplace & 0.63 & Strong \\
\hline Level of understanding of injury preventive measures at workplace & 0.21 & Weak \\
\hline Level of understanding of security regulations at workplace & 0.82 & Strong \\
\hline Level of understanding of the implications of risky work operations & 0.25 & Weak \\
\hline $\begin{array}{l}\text { Level of compliance with rules and regulations guiding the use of } \\
\text { health and safety personnel at workplace }\end{array}$ & 0.18 & Nil \\
\hline $\begin{array}{l}\text { Willingness to participate in the implementation of risk-reduction } \\
\text { action plans in the workplace }\end{array}$ & 0.57 & Strong \\
\hline $\begin{array}{l}\text { Willingness to participate in meetings pertaining to occupational } \\
\text { health and safety measures at workplace }\end{array}$ & 0.62 & Strong \\
\hline $\begin{array}{l}\text { Willingness to participate on training provided by the organisation } \\
\text { on safety regulations on new equipment and other changes } \\
\text { at workplace }\end{array}$ & 0.01 & Nil \\
\hline $\begin{array}{l}\text { Level of understanding and compliance with new accident } \\
\text { preventive measures provided by the company during the periods } \\
\text { of extra workloads }\end{array}$ & 0.08 & Nil \\
\hline $\begin{array}{l}\text { Level of understanding and compliance with protective } \\
\text { regulations on all machines and equipment used at workplace }\end{array}$ & 0.83 & Strong \\
\hline $\begin{array}{l}\text { Level of understanding on the use of personal safety devices } \\
\text { provided at your workplace }\end{array}$ & 0.05 & Nil \\
\hline $\begin{array}{l}\text { Level of understanding on the use of first aid equipment provided } \\
\text { at workplace }\end{array}$ & 0.05 & Nil \\
\hline Ability to take right decision in times of emergencies at workplace & 0.08 & Nil \\
\hline $\begin{array}{l}\text { Ability to take cognizance of a colleague's inability to take right } \\
\text { decisions in times of emergencies at workplace }\end{array}$ & 0.81 & Strong \\
\hline
\end{tabular}

A significant finding from the analysis of the study revealed how each variable contributed to the overall positive strength of the relationship between emotional intelligence and occupational health and safety in the oil and gas industry. Out of the five key success factors of emotional intelligence, only three were found to have a relationship with occupational health and safety in the oil and gas industry, as shown in Figure 5. They included:

(1) Being able to rule your own emotions to facilitate thinking, which had a strong relationship, with a correlation coefficient of $0.76(0.76>0.25)$

(2) Being able to deal with the emotions of others, which had the highest strength of relationship among the five key factors, with a correlation coefficient of $0.91(0.91>0.25)$

(3) Being able to discuss your own emotions accurately, which had a moderate strength of relationship, with a correlation coefficient of $0.33(0.33<0.09)$

This finding indicates that among the five identified key factors of emotional intelligence, only three have the capability to improve occupational health and safety performance in the oil and gas industry, with 'Being able to deal with the emotions of others' having the highest impact. This entails that the employees' awareness of their own emotions and their recognition of the emotions of others does not have any impact on improving occupational health and safety, unless the employees are able to deal with them. Therefore, for oil and gas industry employees to be able to deal with the emotions of others, they will need to be able to rule their own emotions to facilitate thinking and act accordingly $(0.761>$ 0.25). Out of the 14 key success factors of occupational health and safety in the workplace, only 6 were found to be affected by emotional intelligence, as shown in Figure 5. These included the following:

(1) Level of understanding and compliance with protective regulations for all machines and equipment used in the workplace, which was most strongly affected by emotional intelligence, with a correlation coefficient of $0.83(0.83>0.25)$ 
(2) Ability to take cognizance of a colleague's inability to make correct decisions in times of emergencies in the workplace, which was strongly affected by emotional intelligence, with a correlation coefficient of $0.81(0.81>0.25)$

(3) Willingness to participate in meetings pertaining to occupational health and safety measures in the workplace, which was strongly affected by emotional intelligence, with a correlation coefficient of $0.62(0.62>0.25)$

(4) Level of understanding and perception of risks in the workplace, which was also strongly affected by emotional intelligence, with a correlation coefficient of $0.63(0.63>0.25)$

(5) Willingness to participate in the implementation of risk-reduction action plans in the workplace, which was strongly affected by emotional intelligence, with a correlation coefficient of $0.57(0.57>0.25)$

(6) Level of understanding of security regulations in the workplace, which was strongly affected by emotional intelligence, with a correlation coefficient of $0.82(0.82>0.25)$

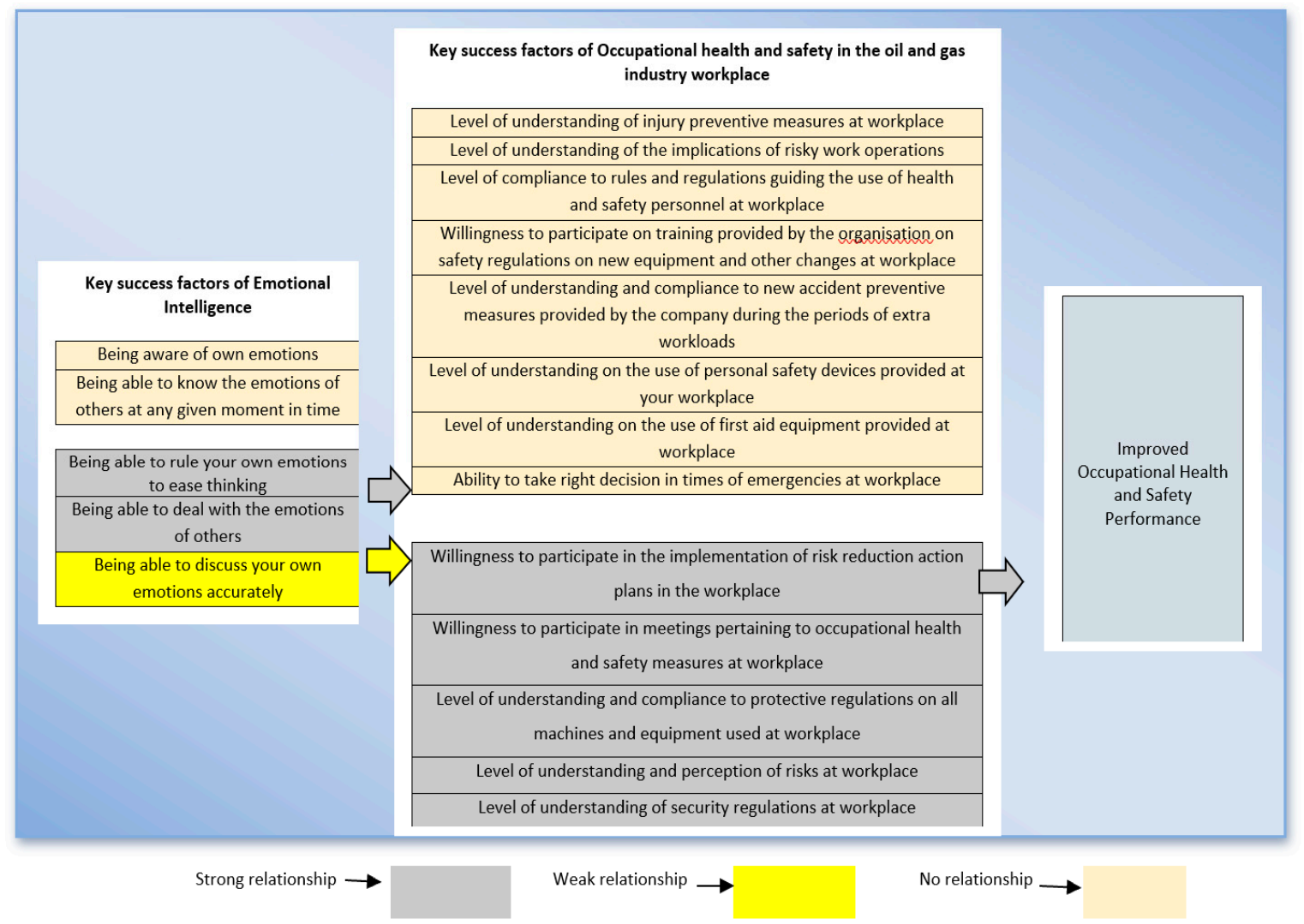

Figure 5. Model showing the extent to which emotional intelligence affects occupational health and safety performance in the oil and gas industry.

Most importantly, the finding that emotional intelligence most strongly impacts on the 'Level of understanding and compliance with protective regulations for all machines and equipment used in the workplace' is an indication that emotional intelligence might be a factor to consider in the recurrence of equipment-related accidents in the oil and gas industry. This finding shows that, despite the level of sophistication associated with health and safety training programmes in the oil and gas industry, it is vital for the competency of the workers that their ability to deal with the emotions of others and be in control of their own emotions should be developed. 


\section{Discussion}

The results of this study are of direct practical relevance to the oil and gas industry. They show that a strong relationship exists between emotional intelligence and occupational health and safety performance. The main outcome of this study is the development of a model that shows the extent to which emotional intelligence affects occupational health and safety performance in the oil and gas industry. The model clearly indicates the key success factors of occupational health and safety that can be improved by the employees' emotional intelligence, as graphically illustrated in Figure 5 . Furthermore, the model shows that not all emotional intelligence factors have the ability to improve an organisation's occupational health and safety performance. From Figure 5, it can be seen that although 'Being aware of one's own emotions' and 'Being able to understand the emotions of others at any given moment in time' are important factors of emotional intelligence in the workplace, they were found to have no impact on improving occupational health and safety performance in the oil and gas industry. Moreover, occupational health and safety factors like 'Level of understanding of injury preventive measures in the workplace', 'Level of understanding of the implications of risky work operations' and the 'Ability to make correct decisions in times of emergencies in the workplace' were found to have no significant relationship with the employees' emotional intelligence. According to Fineman [48] and Joseph et al. [49], many human resource managers in different companies around the globe use emotional intelligence-based assessments in the selection of new employees. This approach has been widely embraced by many organisations as a result of the numerous findings that relate safety performance to emotional intelligence [50-52]. Contrastingly, the model developed by this study shows that not all safety performance factors are affected by emotional intelligence. From a human resource management perspective, the model shows that for the employees' commitment to participating in the implementation of risk reduction and for action plans in the workplace to be effective, employees' emotional dispositions in ruling their own emotions (being in control of one's own emotions) and being able to deal with the emotions of others need to be continuously developed. This also applies to improving employees' commitment to participating in meetings pertaining to occupational health and safety measures in the workplace, understanding and compliance with protective regulations for all machines and equipment used in the workplace and the understanding and perception of risks in the workplace and employees' levels of understanding of security regulations in the workplace [53].

This study also found that the employees' ability to discuss their own emotions accurately has a weak relationship with improving occupational health and safety performance, as shown in Figure 5. This is an indication that, although most of the past oil and gas disasters have been blamed on poor communication $[13,54]$, the underlying problem might be the inability of employees to deal with the emotions of their work colleagues. Put more clearly, the oil and gas industry need to incorporate the development of its employees' 'ability to rule their own emotions' and their 'ability to deal with the emotions of their fellow colleagues' into their regular human resource development programmes to help improve the performance in occupational health and safety practices.

\section{Conclusions}

In this study, 5 key success factors of emotional intelligence and 14 key success factors of occupational health and safety were first derived from a critical review of the past literature. A critical analysis of the opinions of oil and gas industry professionals regarding the extent to which the key success factors of emotional intelligence affect occupational health and safety in the oil and gas industry identified that a strong relationship exists between the two variables. The study went further to identify the key success factors that most contribute to the identified relationship. 'Being able to rule one's own emotions to facilitate thinking' was found to have a strong relationship, 'Being able to deal with the emotions of others' had the strongest relationship among the five key factors. 'Being able to discuss one's own emotions accurately' was found to have a moderate relationship. There is, therefore, a need to incorporate emotional intelligence factors into regular human resource development programmes to help improve workplace health and safety performance. 
Author Contributions: O.A.M. and A.O.I. conceived and designed the experiments and performed the data collection and analysis; A.O.A., S.C.T. and A.O.A. wrote the paper.

Funding: This research received no external funding.

Conflicts of Interest: The authors have no conflict of interest to declare.

\section{References}

1. Cullen, E.T. Effective Training a Case Study From the Oil \& Gas Industry. Prof. Saf. 2011, 56, 40-47.

2. Theophilus, S.C.; Esenowo, V.N.; Arewa, A.O.; Ifelebuegu, A.O.; Nnadi, E.O.; Mbanaso, F.U. Human factors analysis and classification system for the oil and gas industry (HFACS-OGI). Reliab. Eng. Syst. Saf. 2017, 167, 168-176. [CrossRef]

3. Makin, A.M.; Winder, C. Managing hazards in the workplace using organisational safety management systems: A safe place, safe person, safe systems approach. J. Risk Res. 2009, 12, 329-343. [CrossRef]

4. Dollard, M.; Knott, V. Incorporating psychosocial issues into our conceptual models of OHS. J. Occup. Health Saf. 2004, 20, 345-358.

5. Theophilus, S.C.; Abikoye, O.G.; Arewa, A.O.; Ifelebuegu, A.O.; Esenowo, V. Application of Analytic Hierarchy Process to Identify the Most Influencing Human Factors (HFs) and Performance Influencing Factors (PIFs) in Process Safety Accidents. In Proceedings of the SPE/AAPG Africa Energy and Technology Conference, Nairobi, Kenya, 5-7 December 2016.

6. Lieberman, N.P. Process Equipment Malfunctions: Techniques to Identify and Correct Plant Problems; McGraw-Hill: New York, NY, USA, 2011.

7. Ifelebuegu, A.O.; Awotu-Ukiri, E.O.; Theophilus, S.C.; Arewa, A.O.; Bassey, E. The application of Bayesian-Layer of Protection Analysis method for risk assessment of critical subsea gas compression systems. Process Saf. Environ. Prot. 2018, 113, 305-318. [CrossRef]

8. Nolan, D.P. Handbook of Fire and Explosion Protection Engineering Principles: For Oil, Gas, Chemical and Related Facilities; Elsevier Inc.: Burlington, MA, USA, 2011.

9. Mearns, K.; Yule, S. The role of national culture in determining safety Performance: Challenges for the global oil and gas industry. Saf. Sci. 2009, 47,777-785. [CrossRef]

10. Attwood, D.; Khan, F.; Veitch, B. Occupational accident models-Where have we been and where are we going? J. Loss Prev. Process Ind. 2006, 19, 664-682. [CrossRef]

11. Silvestre, B.S.; Gimenes, F.A.P.; Neto, R.E.S. A sustainability paradox? Sustainable operations in the offshore oil and gas industry: The case of Petrobras. J. Clean. Prod. 2017, 142, 360-370. [CrossRef]

12. Griffiths, E. Managing for health. Occup. Health 2010, 62, 14-15.

13. Grier, K.; Sidnell, E. Serious occupational health and safety incidents in the oil and gas industry: Legal issues and recommendations. Alberta Law Rev. 2010, 47, 387-420. [CrossRef]

14. Theophilus, S.C.; Ekpenyong, I.E.; Ifelebuegu, A.O.; Arewa, A.O.; Agyekum-Mensah, G.; Ajare, T.O. A Technique for the Retrospective and Predictive Analysis of Cognitive Errors for the Oil and Gas Industry (TRACEr-OGI). Safety 2017, 3, 23. [CrossRef]

15. DeJoy, D.M. Behavior change versus culture change: Divergent approaches to managing workplace safety. Saf. Sci. 2005, 43, 105-129. [CrossRef]

16. Thory, K. Developing meaningfulness at work through emotional intelligence training. Int. J. Train. Dev. 2016, 20, 58-77. [CrossRef]

17. Alkozei, A.; Schwab, Z.J.; William, D.; Killgore, S. The role of emotional intelligence during an emotionally difficult decision-making task. J. Nonverbal Behav. 2016, 40, 39-54. [CrossRef]

18. Rezvani, A.; Chang, A.; Wiewiora, A.; Ashkanasy, N.M.; Jordan, P.J.; Zolin, R. Manager emotional intelligence and project success: The mediating role of job satisfaction and trust. Inter. J. Proj. Manag. 2016, 34, 1112-1122. [CrossRef]

19. Oginska-Bulik, N. Emotional intelligence in the workplace: Exploring its effects on occupational stress and health outcomes in human service workers. Int. J. Occup. Med. Environ. Health 2005, 18, 167-175. [PubMed]

20. Boyatzis, R.; Rochford, K.; Cavanagh, K.V. Emotional intelligence competencies in engineer's effectiveness and engagement. Career Dev. Int. 2017, 22, 70-86. [CrossRef]

21. Ashkanasy, N.M.; Daus, C.S. Emotion in the workplace: The new challenge for managers. Acad. Manag. Perspect. 2002, 16, 76-86. [CrossRef] 
22. Harper, S.R.; White, C.D. The impact of member emotional intelligence on psychological safety in work teams. J. Behav. Appl. Manag. 2013, 15, 2-10.

23. Spector, P.E. Introduction: Emotional intelligence. J. Organ. Behav. 2005, 6, 409-410. [CrossRef]

24. Green Emotional Intelligence Explained in Ten Easy Steps. Available online: http://dl.dropbox.com/u/ 10042660/GG_Emotional_Intelligence_Explained_in_ten_easy_steps_2011.pdf (accessed on 17 August 2012).

25. Salovey, P.; Mayer, J.D. Emotional intelligence. Imagin. Cogn. Pers. 1990, 9, 185-211. [CrossRef]

26. Goleman, D. Emotional Intelligence; Bantam Books: New York, NY, USA, 1995.

27. Baron, R. The BarOn Emotional Quotient Inventory (EQ-i): Technical Manual; Multi-Health Systems Inc.: Toronto, ON, Canada, 1997.

28. Matthews, G.; Zeidner, M.; Roberts, R.D. Emotional Intelligence: Science and Myth; MIT Press: Cambridge, MA, USA, 2002.

29. Baczyńska, A.; Thornton, G.C. Relationships of analytical, practical, and emotional intelligence with behavioral dimensions of performance of top managers. Int. J. Select. Assess. 2017, 25, 171-182. [CrossRef]

30. Ferguson, F.J.; Austin, E.J. Associations of trait and ability emotional intelligence with performance on Theory of Mind tasks in an adult sample. Pers. Individ. Dif. 2010, 49, 414-418. [CrossRef]

31. Cavazotte, F.; Moreno, V.; Hickmann, M. Effects of leader intelligence, personality and emotional intelligence on transformational leadership and managerial performance. Leadersh. Q. 2012, 23, 443-455. [CrossRef]

32. Decker, B.; Landaeta, R.E.; Kotnour, T.G. Exploring the relationships between emotional intelligence and the use of knowledge transfer methods in the project environment. KMRP 2009, 7, 15-36. [CrossRef]

33. Benjamin, B.; Gulliya, T.; Crispo, A. Emotional Intelligence and Organizational Culture. Insights Chang. World J. 2012, 9, 52-64.

34. Mikolajczak, M. Going Beyond the Ability-Trait Debate: The Three-Level Model of Emotional Intelligence. J. Appl. Psychol. 2009, 5, 25-31. [CrossRef]

35. Siegling, A.; Saklofske, D.; Vesely, A.; Nordstokke, D. Relations of emotional intelligence with gender-linked personality: Implications for a refinement of EI constructs. Pers. Individ. Dif. 2012, 52, 776-781. [CrossRef]

36. Perez, J.C.; Petrides, K.V.; Furnham, A. Measuring trait emotional intelligence. In Emotional Intelligence: An International Handbook; Schulze, R., Roberts, R.D., Eds.; Hogrefe \& Huber Publishers: Cambridge, MA, USA, 2004; pp. 81-201.

37. Mayer, J.D.; Salovey, P.; Caruso, D.R. TARGET ARTICLES: “emotional Intelligence: Theory, findings, and implications". Psychol. Inq. 2004, 15, 197-215. [CrossRef]

38. Goleman, D. The Brain and Emotional Intelligence: New Insights; More Than Sound LLC: Florence, MA, USA, 2011.

39. Kumar, R. Research Methodology-A Step-by-Step Guide for Beginners; Pearson Education: Singapore, 2010.

40. Dawson, C. Practical Research Methods; UBS Publishers: New Delhi, India, 2002.

41. Grant, S.; Kandrack, R.; Motala, A.; Shanman, R.; Booth, M.; Miles, J.; Sorbero, M.; Hempel, S. Acupuncture for substance use disorders: A systematic review and meta-analysis. Drug Alcohol. Depend. 2016, 1, 163:1-163:5. [CrossRef]

42. Quick, T.A. A Blueprint for Success. Occup. Health Saf. 2007, 76, 57-58.

43. Haidari, A. Addressing Engineering Challenges before Disaster Hits. Power Eng. 2011, 115, 8.

44. Clausen, L. Helping Hands. Saf. Health 2007, 175, 50-52.

45. Wiegand, D.M. Exploring the role of emotional intelligence in behavior-based safety coaching. J. Saf. Res. 2007, 38, 391-398. [CrossRef]

46. Hubbard, A.; Henderson, J. A measure of success? Chem. Eng. 2011, 836, 24-25.

47. Weisinger, H. Emotional Intelligence at Work; Jossey-Bass: San Francisco, CA, USA, 1998.

48. Fineman, S. Getting the measure of emotion-And the cautionary tale of Emotional intelligence. Hum. Relat. 2004, 57, 719-740. [CrossRef]

49. Joseph, D.L.; Jin, J.; Newman, D.A.; O’Boyle, E.H. Why does self-reported emotional intelligence predict job performance? A meta-analytic investigation of mixed EI. J. Appl. Psychol. 2015, 100, 298-342. [CrossRef]

50. Moon, T.; Hur, W. Emotional intelligence, emotional exhaustion, and job performance. Soc. Behav. Person. 2011, 39, 1087-1096. [CrossRef]

51. Van der Linden, D.; Tsaousis, I.; Petrides, K. Overlap between General Factors of Personality in the Big Five, Giant Three, and trait emotional intelligence. Person. Individ. Differ. 2012, 53, 175-179. [CrossRef] 
52. Sunindijo, R.Y.; Zou, P.X. The roles of emotional intelligence, interpersonal skill, and transformational leadership on improving construction safety performance. Construct. Econ. Build. 2013, 13, 97-113. [CrossRef]

53. Lu, C.S.; Kuo, S.Y. The effect of job stress on self-reported safety behaviour in container terminal operations: The moderating role of emotional intelligence. Transp. Res. Part F 2016, 37, 10-26. [CrossRef]

54. Khan, F.I.; Amyotte, P.R. Inherent safety in offshore oil and gas activities: A review of the present status and future directions. J. Loss Prev. Process Ind. 2002, 15, 279-289. [CrossRef]

(C) 2019 by the authors. Licensee MDPI, Basel, Switzerland. This article is an open access article distributed under the terms and conditions of the Creative Commons Attribution (CC BY) license (http://creativecommons.org/licenses/by/4.0/). 